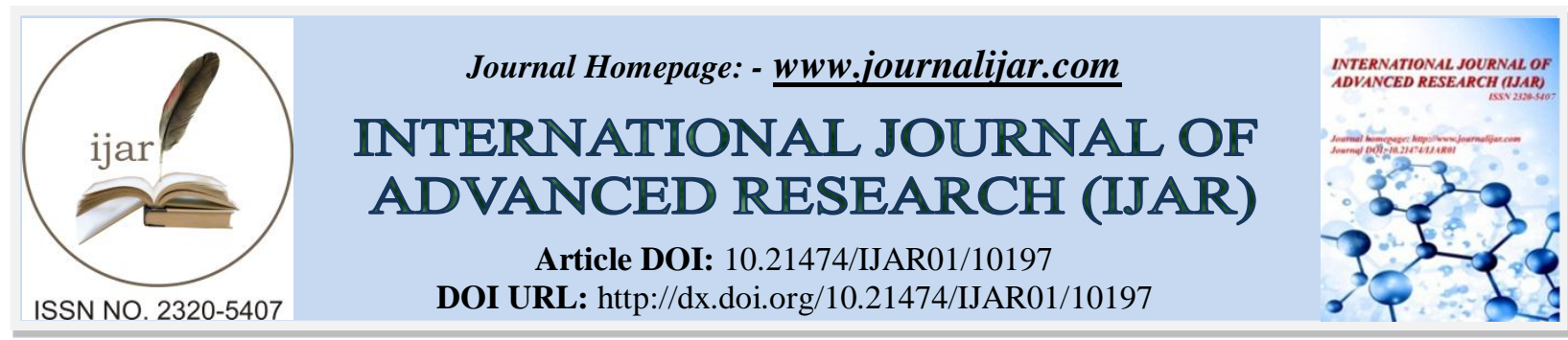

RESEARCH ARTICLE

\title{
POLICY AND IMPLEMENTATION GAP : A MULTI - COUNTRY PERSPECTIVE
}

\section{Gina Teddy ${ }^{1}$, Martina Lembani ${ }^{2}$, Boroto Hwabamungu ${ }^{2}$ and Dintle Molosiwa ${ }^{3}$}

1. Health Policy and Systems Division, School of Public Health and Family Medicine, University of Cape Town, Anzio Road, Observatory, 7925, Cape Town.

2. School of Public Health, University of the Western Cape, Robert Sobukwe Road, Private Bag X17, Bellville 7535, Cape Town, South Africa.

3. Public Health Management, Institute of Development Management, Mobuto Road, P.O.Box 1357, Gaborone Botswana.

\section{Manuscript Info}

Manuscript History

Received: 10 October 2019

Final Accepted: 12 November 2019

Published: December 2019

\section{Key words:-}

Implementation Gap, Policy Analysis, LMICs, Sub-Saharan Africa, Ghana, Malawi, Botswana, Health Policy, Health Systems

\section{Abstract}

Background: Widespread evidence on implementation indicates that health policies once adopted are not implemented as envisioned and do not always achieve the intended outcomes. The challenges associated with policy implementation gaps have been widely attributed to several factors, ranging from problematic policies to lack of governance and resources. Yet developing countries continue to experience these problems in their bid to translate policy into outcomes, including reduced health care and health inequity. This study seeks to understand the complexity associated with health policy implementation and why implementation gaps remain a challenge for low-and-middle income countries.

Methods: A thematic synthesis of findings from three $\mathrm{PhD}$ studies, each focusing on national health policies across three African countries (Malawi, Ghana and Botswana) was undertaken to provide insight into the complex processes and factors influencing implementation outcomes. We developed 'descriptive themes' and 'analytical themes' to elucidate and explain key factors leading to policy implementation gaps guided by theoretical and empirical literature. Through an iterative process of data extraction, core themes from the studies were thematically analysed to highlight the contributing factors leading to implementation gaps.

Results and discussion: These three cases provided experience of the system-wide complexity associated with implementing national health policies that seek to promote health care equity. We identified overarching factors contributing towards implementation gaps and policy failures across the three countries which include issues of: collaboration, discretionary powers, resources, governance and sociocultural appropriateness. These factors are not exclusive but interlinked, illustrating a complex interaction among actors with the processes and context of implementation. The results of our analysis also showed that health policy implementation occurs in a highly dynamic and complex environment that is constantly being shaped and

Corresponding Author:- Gina Teddy 
influenced, in unpredictable ways by external and internal factors to the system with people and relationships at the core of these factors.

Conclusion: We concluded that implementing health policies is a complex phenomenon that triggers unintended consequences, and that intangible factors are often ignored by policymakers, yet have critical impact on policy processes and outcomes. Therefore, policymakers need to rethink the process of implementing health policies, engaging actors and addressing the multiple factors confronting actors when putting policies into practice.

Copy Right, IJAR, 2019,. All rights reserved.

\section{Introduction:-}

Implementation experience in low-and-middle income countries (LMICs) shows that policies once adopted, are not always implemented as envisioned and do not always achieve intended results [1,2,3]. The process of translating policy into outcomes, practice or specific programs has long been recognised by policy makers, governments, practitioners and researchers as fraught with difficulties, which impact on intended outcomes or lead to failures. Key stakeholders in LMICs are increasingly concerned with policy failures, the widening gap between policy intentions and implementation and why these challenges are difficult to fix or prevent [4]. Understanding the nature of policy implementation in LMICs is relevant to unpacking the causes of this challenge and to help ensure available evidence is translated into tangible solutions to address prevailing poor health outcomes and failing health systems. Effective implementation of potent policies is central to addressing health system constraints. Poor implementation of carefully thought national policies and strategic plans/guidelines in LMICs countries has been attributed to a number of factors including limited leadership skills, poor collaboration/engagement of appropriate actors or stakeholders [5]. Literature shows similarities in terms of implementation challenges among LMICs, however this study uses three policy cases from Ghana, Malawi and Botswana to demonstrate the complexity associated with health policy implementation and why implementation gaps are increasingly widening more specifically in sub-Saharan Africa.

\section{Policy Implementation Challenges:}

Saetren (2005) states that there is a dearth in literature on policy implementation in Africa where they indicate that only $4 \%$ of the research on policy implementation globally has been conducted in Africa [6,7]. This view is shared by Erasmus et al (2014) who concluded that there is still little research on health policy implementation in these settings [8]. They found the available research to be fragmented, of limited depth and diversity, showing a wide range of health system elements that provide different suggestions for improving policy implementation. The authors suggest the need for consolidation of the existing body of work, drawing more on theoretical frames and concepts to deepen the analysis on the concerns and questions affecting policy implementation [8]. Although the trend in research on health policy implementations in LMICs seems to be improving as revealed by the annotated bibliography authored by Irani and colleagues (2015), fragmentation still remains a challenge [9].

Beland and Ridde (2016) state that one of the reasons for policy implementation failures is lack of shared ideas among key actors such as professionals and street level bureaucrats who are tasked with policy implementation responsibilities. Irani and colleagues (2015) use five sub-sections to clarify the process and other related aspects involving the implementation of policies. These include; institutions, relationships and power dynamics; capacity; financing; strategic planning and policy barrier analysis and monitoring and accountability. Others have highlighted implementation issues including the role of social organisation and political culture of a particular society as demonstrated by the work of Atkinison et al (2000) conducted in Brazil using three case studies of district health systems where they identified space for autonomy and local voice for acceptable practices and accountability as some aspects that are key in implementation of programme [10]. Related to this, although from a different perspective, is the key role of autonomy of states for a federal government like Nigeria where it has been difficult to establish a national framework to support a primary health care for all [11]. Another issue that is highly cited is power relations between health workers and patients, discretionary power and managerial practices [12, 13, 14]. The Simwaka (2008) study was conducted in Malawi where it was found that health workers often exercise power in relation to patients and that patients simply yield to the health workers behaviours. In this study, an element of managerial practices was also found to be influential in the policy implementation process as it either motivated or demotivated the health workers in their performance regarding the enrolment of HIV clients on antiretroviral therapy 
(ART). The other two studies $[13,14]$ conducted in South Africa also reveal some exercise of power at the local levels that impacted on implementation. Leadership and coordination, tensions between vertical and horizontal approaches to health improvements were highlighted by various scholars [15, 16, 17]. Other factors that influence policy and identified by different authors include, health governance, improving accountability and transparency, reducing corruption, the role of street level bureaucrats as well as conflicts between actors and power relations and communication challenges $[18,19]$.

There is also a large body of literature under policy implementation that is highly linked to research uptake to inform evidence based policy implementation also known as the know-do-gaps [20, 21, 22, 23]. However, this paper does not address this aspect of policy implementation. As shown in the preceding literature, most of the studies tackled one or two specific policy implementation issues from various perspective, also supported by Erasmus et al (2014). This paper therefore endeavours to fill this gap by consolidating the various aspects of policy implementation that affect health policy outcomes in sub-Saharan Africa using the three case studies. The three case studies evaluate significant national health reforms that seek to promote health care equity goals and have system-wide effects for service provision and client engagement.

\section{Policy implementation Nature and processes:}

Policy implementation, however defined, has been proven to be complex, involving a set of activities, resources and operations undertaken by various actors toward the achievement of goals and objectives defined in an authorized policy [24]. There are several policy analysis tools that have been used to explain the concept of policy implementation. Some of these are concerned with the policy itself, in terms of content, actors, context and process such as the policy triangle [25]. Others have been developed from the implementation science approach [26]. These approaches are sub-divide into three categories; those describing the process of translating research into practice known as process model theories; those explaining what influences implementation outcomes known as determinant frameworks (or classic /implementation theories); and finally, those evaluating implementation termed as evaluation frameworks [26]. The systems thinking, top-down and bottom-up approaches, and complex adaptive systems frameworks have been used to explain implementation.

The Health Policy Initiative, Task Order 1, a USAID funded initiative used a Policy-to-Action Framework to illustrate the dynamic nature of the policy process. In their summary report, they describe the policy process as an iterative process that 'unfolds differently in different contexts'. They further expressed the interdependence of several elements that need to be mixed together-sometimes without any order, at the same time in a repeated manner in order to achieve effective policy implementation. This, they indicate requires special skills to bring all the different elements together and that entails "understanding policy issues, the context, and stakeholders; anticipating potential roadblocks; seizing windows of opportunity; and building and sustaining commitment, capacity, and resources over time" [27:5]. Indeed, in the real world, policy implementation is multi-faceted. Therefore, the development of implementation strategies must involve stakeholder groups such as government, implementing and provider organisations, individual providers and front-line workers, communities and households and other actors whose action or inaction shape policy [28]. These stakeholders have different power levels and greatly affect policy implementation in the different roles and functions they perform during implementation [29].

This paper is mostly concerned with determinant frameworks that facilitate understanding of why implementation fails despite having a great policy on paper. The determinant frameworks address issues such as organizational contexts and practices, culture, organisational readiness for innovation, networks and communication, support and resource barriers, system and process barriers, community level factors, staffing, incentives physical environment, health care professional behaviour change and adherence to clinical guidelines among other issues [26].

Although not directly an implementation theory, it worth highlighting that the way the policy is formulated could also have an impact on implementation. For instance, the top-down theorists present implementation as a linear process where policies developed by policymakers are simply percolated down the system by public officials and administrators following policy instructions [30, 31]. While the bottom-up theorists present implementation as a process of interaction and negotiations that may take place over time among the policy actors [32]. However, both approaches have limitation in practice. Irrespective of the approach, the implementation strategies adopted must recognise the many other factors that shape policy action, particularly within the complexity inherent in the health systems and implementation itself. Nilsen (2015) indicate that determinant frameworks are integrative in nature and recognise that "implementation is a multidimensional phenomenon with multiple interacting influences" [29:5]. This 
is a very important aspect when unpacking implementation failures because health systems are known to have different components, closely knitted relationships and interactions that determine the system's behaviour [33]. The complexity of the health systems is further embedded in their organisational structure, context and the related interactions at the interpersonal (or micro), organisational (or meso) and national (or macro) levels [34].

The health system's intangible software (values, culture, power, communication, etc.) is particularly essential in understanding how these invisible forces affect and shape the system's behaviour [35]. The interaction between the different actors, the intangible software and other factors can lead to unintended policy implementation consequences which, as argued by Gilson \& Raphaely (2008) cannot be ignored in health policy implementation interventions [36]. This paper contributes to the literature on why policy implementation fails and how to improve on implementation processes to increase success of policy implementation especially in Africa.

\section{Setting of the Three Cases: Ghana, Malawi and Botswana:}

This provides the background of the policies in Ghana, Malawi and Botswana. It briefly explains the health policies and research focus (or empirical $\mathrm{PhD}$ studies [37, 38, 39] used to analyse the complexities associated with implementation in the three countries in sub-Saharan Africa. It lists some of the challenges associated with the implementation of these policies with detailed examples in the findings.

\section{Ghana:}

This study explored the implementation of the National Health Insurance Scheme (NHIS) when it was rolled out using multiple case studies to explore systemic and individual factors influencing implementation at the national, regional, districts, communities and facility levels. In Ghana, a National Health Insurance Policy was introduced in 2001 to replace the out-of-pocket payments (i.e. user fees for healthcare) in operation for over two decades by providing a specified minimum healthcare benefit package free at the point of service use [40:7). The policy was launched under the National Health Insurance Scheme (NHIS), a program aimed at promoting pro-poor financing policies and equitability in healthcare access. The NHIS provided a prepayment financing option which removes the cost of care and financial barriers at the point of service use so that access is improved for those who really need it [40]. This was rolled out nation-wide in 2005 with the National Health Insurance Authority set up to have overall mandate to implement and regulate the NHIS. The objective was to enable all residents of Ghana to belong to one, or more, of the recognized types of insurance schemes [40: 1]: a Social-type Health Insurance Scheme (i.e. District Mutual Health Insurance Schemes and Private Mutual Health Insurance Schemes) or a Private Commercial Health Insurance Scheme. The Authority subsequently reported an increase in enrolment and member from $18 \%$ and $11 \%$ respectively in 2006 to $62 \%$ and $48 \%$ in 2009 [41]. Despite the gradual increase in enrolment, the scheme has been experiencing problems among which are; poor communication among actors for policy and implementation directives, delayed claims payment, shortage of drugs, political interference, high workload for health providers, limited human resources, unauthorised charges among others. Using multiple case studies and qualitative techniques, the perspectives, experiences and role of actors such as the implementers, stakeholders, bureaucrats and policy beneficiaries provided an insight into implementation and health policy adoption. This study explored the processes from policy to practice at the multiple levels to enable understand the operation of the NHIS in its early years between 2005-2007. It also assessed how far the government was towards achieving their key objective of providing "an acceptable quality of a package of essential health services without out of pocket payment being required at point of service use" [40:7].

\section{Malawi:}

This study focused on the effectiveness of HIV and AIDS service provision in Malawi with a special interest on antiretroviral treatment (ART) by comparing the health outcomes among patients receiving their treatment from the government, the non-profit sector and the for-profit sector health facilities. Malawi is one of the countries in subSaharan African with high HIV prevalence rate. Its first HIV infection case was identified in 1985 . By 1999 the prevalence rate had accelerated to $16.2 \%$ and declined to $12 \%$ by 2004 [42]. However, by this time only $3 \%$ of the patients that needed ART had access to this treatment because only a few government clinics offered the service and many could not afford the prohibitive costs associated with this treatment from the private sector. Therefore, in 2004, the Malawi government decided to scale up the free universal access ART programme nationwide to promote equity and increase access for this essential service. However, due to limited human resource capacity, rapid scaleup was a challenge. To deal with this problem, the government developed strategies to ensure high coverage including task-shifting and inclusion of all stakeholders i.e. the non-profit and the for-profit sector. This increased the number of ART sites from nine in December 2003 to 417 by December 2010. This correspondingly led to the increase in the number of patients enrolling in the ART programme from $3 \%$ to $63 \%$ over the same period. The 
National AIDS Commission (NAC) has the overall mandate of managing the HIV and AIDS programme including the ART policy. Although ART is free, those accessing ART services in for-profit sector and non-profit sector facilities (without government subsidies) are required to pay approximately US\$ 3.00 for administrative fee per visit. This therefore partly affect access of ART services from these for-profit sector facilities. The aim of this study was to analyse the extent to which NGOs contribute to provision of HIV/AIDS services in Malawi by using a comparative approach. This study analysed quantity, quality and cost-effectiveness of the HIV and AIDS services provided by the non-profit sector in comparison to the government and the for-profit sector with a special focus on antiretroviral treatment (ART).

\section{Botswana:}

This study analysed women's access to and utilization of maternal and child health services in the context of the National Policy on HIV and AIDS, particularly the Prevention of Mother-to-child Transmission (PMTCT) of HIV/AIDS. First developed in 1992 and revised in 1998, Botswana's National Policy on HIV and AIDS took on a multi-sectoral response to the epidemic to involve the local level. The PMTCT program represented the country's universal coverage to HIV prevention and care services, where all women attending ante-natal clinics in public health facilities will receive PMTCT services and automatically be enrolled in the ARV programme. After piloting the feasibility of the program in the country's two largest cities in 1999, the PMTCT program was rolled out across the country by 2002. As a key implementation strategy, PMTCT was immediately integrated into routine sexual and reproductive health services especially, maternal and child health services throughout the country's public health facilities. The PMTCT programme was centralized by the Ministry of Health, and mainly coordinated from the Department of HIV/AIDS Prevention, Treatment and Care in the Ministry of Health. By 2007, the country managed to reduce vertical transmission of the HIV virus from 20 - 40 percent in 2001 to 7 percent. Using a mixed method approach, the study explored women's perception of access and utilization of maternal and child health services. Women's access to and utilization of health services was explored in view of the National Policy Guidelines and Service Standards for Sexual and Reproductive Health as well as the National PMTCT Policy Guidelines. Guided by the theory of trust and its role on utilization of health services, the study explored systemic and individual factors influencing women's access to health services for PMTCT.

Table 1:- Country Cases and Policy Focus.

\begin{tabular}{|c|c|c|c|}
\hline Description & Malawi & Ghana & Botswana \\
\hline Policy name & $\begin{array}{ll}\text { Free } & \text { Universal Antiretroviral } \\
\text { (ART) } & \text { Programme }\end{array}$ & $\begin{array}{l}\text { National Health Insurance } \\
\text { Scheme }\end{array}$ & $\begin{array}{l}\text { Botswana National Policy } \\
\text { on HIV/AIDS }\end{array}$ \\
\hline $\begin{array}{l}\text { Legislation } \\
\text { Policy framework } \\
\text { guiding the } \\
\text { implementation }\end{array}$ & $\begin{array}{l}\text { HIV and AIDS } \\
\text { Framework (NSF) and } \\
\text { HIV andional } \\
\text { Framework (NAF). }\end{array}$ & $\begin{array}{lrr}\text { National Health } & \text { Insurance } \\
\text { Act } 650 \text { and } & \text { National } \\
\text { Insurance } & \text { Legislative } \\
\text { Instrument } & \end{array}$ & $\begin{array}{l}\text { Sexual and Reproductive } \\
\text { Health }\end{array}$ \\
\hline $\begin{array}{l}\text { Program/ Project } \\
\text { (s) }\end{array}$ & $\begin{array}{l}\text { National HIV Prevention } \\
\text { Strategy; Prevention of Mother to } \\
\text { Child Transmission (PMTCT); } \\
\text { ART scale up plan; National } \\
\text { Impact Mitigation Strategy; \& } \\
\text { National Plan of Action }\end{array}$ & $\begin{array}{l}\text { National Health Insurance } \\
\text { Scheme }\end{array}$ & $\begin{array}{l}\text { Prevention of Mother-to- } \\
\text { Child transmission } \\
\text { (PMTCT) of HIV }\end{array}$ \\
\hline $\begin{array}{l}\text { Year of } \\
\text { implementation }\end{array}$ & 2004 & $2004 / 5$ & 1999 \\
\hline $\begin{array}{l}\text { Policy emanated } \\
\text { from }\end{array}$ & $\begin{array}{l}\text { Government supported by } \\
\text { various development partners }\end{array}$ & $\begin{array}{l}\text { The Government (rooted in } \\
\text { political campaign) }\end{array}$ & $\begin{array}{lr}\text { Government } & \text { supported by } \\
\text { various } & \text { development } \\
\text { partners } & \end{array}$ \\
\hline $\begin{array}{l}\text { Oversight } \\
\text { organization }\end{array}$ & $\begin{array}{l}\text { The Ministry of Health }- \text { HIV } \\
\text { and AIDS Unit and National } \\
\text { AIDS Commission }\end{array}$ & 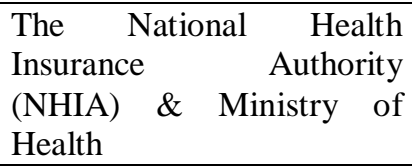 & Ministry of Health $(\mathrm{MoH})$ \\
\hline $\begin{array}{l}\text { Implementing } \\
\text { actors }\end{array}$ & $\begin{array}{l}\begin{array}{l}\text { Multiple actors at all levels } \\
\text { including } \\
\text { organizations }\end{array} \begin{array}{r}\text { non-governmental } \\
\text { Community-based } \\
\text { Corganization }\end{array} \\
\end{array}$ & $\begin{array}{l}\text { Multiple actors at national, } \\
\text { regional and district levels } \\
\text { and international level } \\
\text { interest }\end{array}$ & $\begin{array}{l}\text { Multiple actors at } \\
\text { international, national, } \\
\text { district, facility and } \\
\text { community levels }\end{array}$ \\
\hline
\end{tabular}




\begin{tabular}{|c|c|c|c|}
\hline & $\begin{array}{l}\text { (CBOs), } \\
\text { organizations (FBOs) and private } \\
\text { for-profits }\end{array}$ & & \\
\hline $\begin{array}{l}\text { Relevance to } \\
\text { Equity }\end{array}$ & $\begin{array}{l}\text { Promote improved access to HIV } \\
\& \text { AIDS services to all affected } \\
\text { persons nation-wide by removing } \\
\text { both financial and geographical } \\
\text { barriers }\end{array}$ & $\begin{array}{l}\text { Promote universal access to } \\
\text { basic healthcare by } \\
\text { removing financial barriers } \\
\text { at the point service and } \\
\text { providing cross- } \\
\text { subsidization for funding } \\
\text { and service provision }\end{array}$ & $\begin{array}{l}\text { Promote improved access } \\
\text { to maternal and child } \\
\text { health care services } \\
\text { nation-wide in order to } \\
\text { reduce mother to child } \\
\text { transmission of HIV \& } \\
\text { AIDS. }\end{array}$ \\
\hline
\end{tabular}

\section{Methods:-}

To understand the challenges of policy implementation in low-and-middle income countries, a thematic interpretive synthesis of the three PhD studies described above (see Table 1) was conducted. As indicated, these studies focused on the implementation of national health policies and programmes across three African countries Ghana [37], Malawi [38], and Botswana [39]. This study builds upon the increasing interest and appreciation of the value of qualitative synthesis of previous primary research, especially in Health Policy and Systems Research (HPSR) and other fields in bringing together, often fragmented research findings that could otherwise be synthesised for a more holistic understanding [37, 38, 39].

\section{Data extraction:}

We borrowed a number of key elements from the Thomas and Harden's (2008) thematic synthesis process to aid our synthesis [44]. Thomas and Harden's thematic synthesis conventionally has three key steps to follow to bring together and integrate the findings of multiple qualitative studies. These steps include line-by-line coding of text, development of descriptive themes and generation of analytical themes. Steps one and two of the Thomas and Harden's approach employs principles of grounded theory, whereby concepts are grounded theory, whereby concepts are grounded into their context by checking to ensure that transfer of themes and concepts from one situation to another is valid [44].

While we did not do coding line-by-line, we engaged especially in a rigorous iterative process that enabled us to develop descriptive themes from across the three studies and finally analytical themes to form the factors explaining implementation gaps. 
Fig 1: Steps for meta-synthesis of selected studies

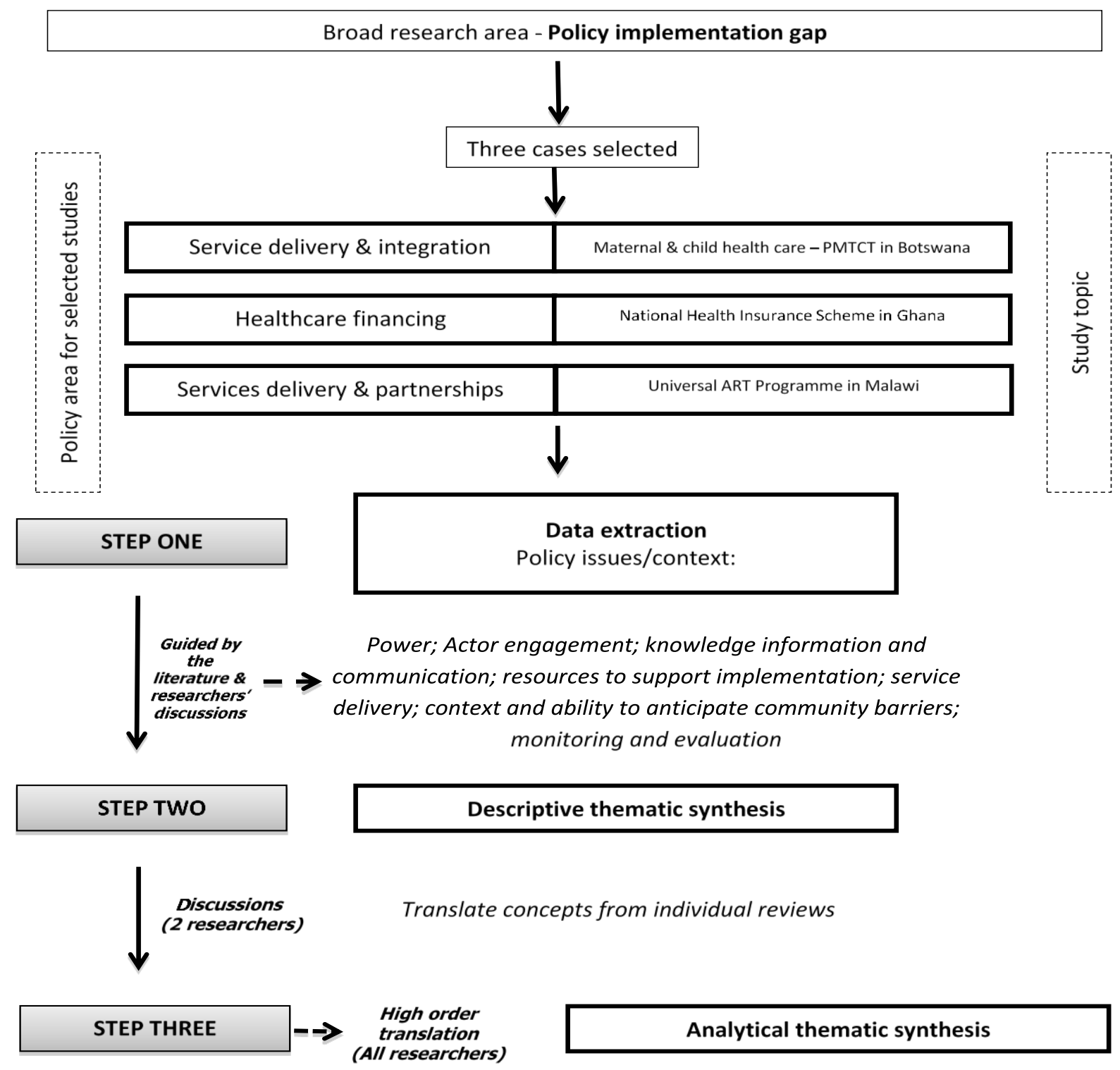

Step 1: This step involved an initial meeting discussion among all three researchers where various policy implementation failure factors in the general literature were discussed. Following this discussion, the researchers agreed on a number of selected factors that were to be used to guide data extraction from the respective $\mathrm{PhD}$ studies. Some of these factors included power; actor engagement; knowledge information and communication; resources to support implementation; service delivery; context and ability to anticipate community barriers; monitoring and evaluation. Each researcher individually extracted data from their $\mathrm{PhD}$, and wrote a detailed summary which was organised around the above factors. To aid this extraction, the researchers aimed to answer the question: How countries in sub Saharan Africa are increasingly following evidence-based policy reforms and strategies yet still fail to acquire maximal/optimal success in policy implementation - more specifically, what are the most common and observable pit-falls in policy implementation?

Step 2: Following the initial data extraction from across the three $\mathrm{PhD}$, two researchers read through the summaries generated and developed descriptive themes emanating from these. A total of nine descriptive themes were generated by this process and included multiple actor engagement, communication, information and policy knowledge; trust and policy acceptance; supervision, monitoring and evaluation; frontline workers; resource 
constraints; governance, leadership and political power. These were then discussed and agreed upon by all three researchers who also had to verify (agree) that the themes illustrated findings and other discussions found in their studies. An initial summary organised around these descriptive themes was then written by the lead author and reviewed by all. More specifically, the primary researchers especially helped to elucidate meanings by providing relevant and supporting quotations, findings and other information from their respective $\mathrm{PhD}$ studies to the summary.

Step 3: The last step which also involved all researchers was a process of going beyond the findings of the primary studies to provide a synthesis - a high order interpretation of the summary to provide new concepts and in-depth understanding. Thomas and Harden (2008) suggest that this process represent the equivalent of third order interpretation in meta-ethnography. This stage especially represented researchers' interpretation of the 'findings' summarised from the primary studies to generate new concepts and explanations - analytical themes. We extend that this also relates to Noblit \& Hare's (1988) reciprocal translation analysis where concepts/themes from individual studies are translated to achieve overarching concepts or metaphors [47]. This process yielded a total of five analytical themes that are discussed in detail in the result section. Figure 1 below provides an outline of the steps followed by the team.

\section{Selection of the case studies:}

Three studies were selected from the outset not only for practical reasons, including time but also for heterogeneity aimed at including different levels of the health system, different actors, in different settings and at different times as well as different policy reforms and issues to maximise the diversity relevant to our enquiry. They all represent indepth study of significant health reforms, report experiences of system-wide effect, consider complexity associated with programmatic intervention. They all consider issues of service provision and client engagement. The contextual differences among the cases is that they represent experiences in Southern versus West Africa, system-wide intervention of health financing versus HIV/AIDs programmatic interventions (Prevention of Mother to Child Transmission (PMTCT) and Antiretroviral Therapy (ART)) with systems effect. These countries have comparatively stable health systems that have undergone various national reforms and the studies were conducted during the time of stable governance. The aim of the study was not to provide an exhaustive summary of data, neither was the purpose of the study to aggregate data from the three studies on policy implementation gap/failure, but rather to identify and develop concepts to provide a comparative understanding of issues around policy implementation gap across various contexts.

\section{Methodological Limitations:-}

This secondary data synthesis comes from the three $\mathrm{PhD}$ studies that had previously been thematically analysed. The challenges of doing this type of synthesis is selection bias of the themes, omission of contextual factors and the lack of generalisability of qualitative findings. We make no assumption that the findings from the different studies are generalizable across context because context have significant implication to policy implementation and outcome, but it provides a conceptual basis for analysis across context. To address this, the approach used was highly iterative and benefited from the multidisciplinary nature of the research team. This further addressed the problem of re-analyzing qualitative studies and the critique associated with the use of meta-synthesis, that it involves inadequate contextualisation of the various studies [47]. The critique was overcome as members of the research team were also the primary investigators of the selected $\mathrm{PhD}$ studies, therefore helping to ensure that meanings and understanding in context were not lost. At the same time, providing a theoretical framework for generalisability. 
Fig 2: Common factors contributing towards policy-implementation gap

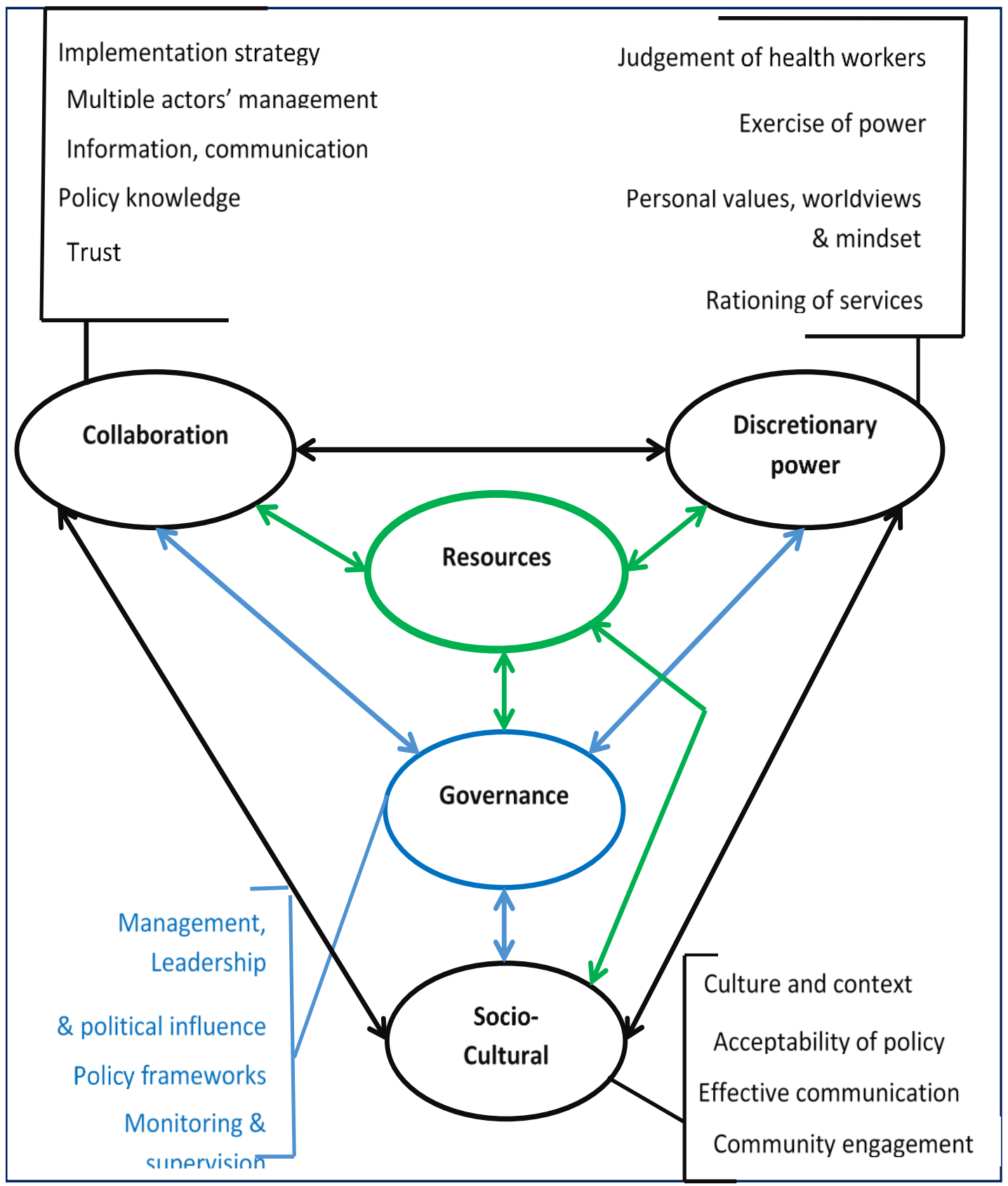

\section{Results:-}

Across the three studies, five overarching/analytical factors were identified to be causing the gaps between policy intention and implementation. These factors are: collaboration, discretionary power, resources, governance and socio-cultural appropriateness. Each of these factors are analytical themes derived from several descriptive subthemes. These subthemes include multiple actor engagement, communication, information and policy knowledge; trust and policy acceptance; supervision, monitoring and evaluation; frontline workers; resource constraints; governance, leadership and political power. Several of these sub-themes are interlinked and are relevant across the analytical themes. These analytical themes are presented in Fig 2 to illustrate the complex interactions among all the factors in the process of policy implementation. These factors are explained in detail in the following sections. 


\section{Collaboration:}

Collaboration as a theme defines the processes of building coordination or partnership among multiple actors to provide joint consideration for policy implementation purposes. This is particularly important because the strategies adopted by the implementing agencies required multiple actors to be involved at different levels. Therefore, how actors negotiate the relationship for collaboration; use information, communication and policy knowledge; and develop trust for implementation of the policies may create gaps when not effectively managed.

The three countries adopted a top-down approach for the implementation of their respective policies (the Free ART in Malawi, NHIS in Ghana and PMTCT in Botswana), where central level actors designed, formulate policies and made key decisions with little or no engagement with implementing actors. This became problematic in Ghana because institutions such as the National Health Insurance Authority mandated to implement the Scheme and coordinate actors such as service providers, financial institutions, regulatory bodies, donor agencies, district schemes among others across the levels of operations failed to effectively communicate, engage and partner with key actors. This led to gaps in resources and information sharing as explained by a donor agent below:

"It is not a matter of coordination with the Council [NHIA], you have to initiate a meeting because no one is coming in to tell you anything so for us not to waste resources in duplicating programs from the government or the Council, we initiate a meeting with them to find out what is going on as well as to tell them what we are also doing. There is nothing like coordination, no, there is no coordination, no meeting, they don't correspond [circulate] reports and all those things which keep us in the dark on how crucial our support is required or not by the schemes...." (Donor: Ghana)

Similarly, in Malawi and Botswana, the Ministries of Health working through the National AIDS Commission (NAC) and the National AIDS Coordinating Agency (NACA) respectively, worked closely with NGOs, donor agencies and health providers on HIV/AIDS advocacy for community engagement, resource mobilization and service delivery. These multiple actors, required efficient and transparent information sharing. Furthermore, in Malawi, HIV and AIDS financing is heavily dependent on external donor support, constituting $98 \%$ of its HIV treatment funds. But the lack of transparency and inconsistencies in engaging with the National AIDS Commission (NAC) had challenged their relationship with donor agencies and NGOs. This affected the partnership towards capacity building and funding for HIV and AIDS.

A multi-sectoral approach towards dealing with the HIV and AIDS pandemic in Botswana meant that managing the wide range of actors functioning to provide funding, specialized services, health services with direct or complementary impact to the PMTCT services (including task-shifting) was a challenge. For instance, lay counsellors and health workers in the facilities use different protocols and records because are were seconded or employed and accountable to different actors such as MoH, NGOs like PEPFAR and research institutes. PMTCT patients who were registered at the MCH also needed to be on the ART register at Infectious Disease Control Clinic (IDCC). This was particularly challenging for the doctors and nurses required to consolidate these information for service provision and record keeping for follow-up purposes.

For actors to ensure effective collaboration they emphasised the need for information sharing, communication and active consultation. Yet communication between and across actors or organisations was inadequate at various levels. Between policy makers and implementers in Ghana, for instance, there was very limited communication of information and creating a gap in knowledge on activities and functions meant to be collaborative. This was expressed by the financial institution responsible for collecting as well as the Ministry of Health respectively.

There is no official communication between us and the Council [NHIA] ... There is legislation which mandates us to collect the money.... Basically, there has been no interaction; we don't even have representation from the council at our annual meetings anymore, even though we are an agency for [National Health Insurance Levi] collection... (Financial Institute: Ghana)

... Although the NHIC is supposed to be reporting frequently to the $\mathrm{MoH}$, the administrative and executive team members took decisions, and implemented them without consulting or informing the $\mathrm{MoH}[\ldots] \ldots$ and this formed the main source of conflict within the central institutions of the scheme such as between MoH and NHIC. (Ministry of Health: Ghana) 
In Malawi, the high level of coordination required among actors for HIV and AIDS services mandated timely and effective communication on directives, policies and operations among actors within and across the levels of operations. But this was problematic especially for services providers. Most service providers and patients were not aware that ART services can be accessed from private facilities at a minimal fee as well as patients' rights towards demanding services. This created utilisation pressures at the public facilities and prevented service users from accessing readily available ART services. Also, service users lacked knowledge of the Free ART as being comprehensive and accessible across both public and private facilities. For instance, three years after the start of the free ART programme some community did not even know about the existence ARVs and let alone the programme as shown in the following statement

“...we don't even know how they look like (ARVs). So if someone was selling and told us they are malaria drugs, we would buy them". (Community Member: Malawi)

Interviews with community members in the community that included Community Based Care volunteers revealed that out of 40 participants only seven had ever heard of ARVs. Of these seven only four had a clear understanding of these ARV and their major sources of information was the radio (ca. Ntata, 2007)

In Botswana, poor communication from the national level regarding protocols for adherence, defaulting and loss-tofollow up was a major challenge for the facilities and the PMTCT program. There was no official definition of adherence or defaulting under the PMTCT program in Botswana leaving facilities to use their discretion despite the implication of this to the PMTCT service described below:

Remember also that with ART the required level of adherence is 95 percent, very high, so any defaulting, even if it is just missing one dose or two doses of required medication, can affect that required percentage level for effective adherence. (Service provider: Botswana)

Related to this, different donors in Malawi had different priorities and decided who they wanted to work with and how their resources were to be utilised. Some of the donors insisted that the big NGOs work in partnership with Community Based Organisations (CBOs). However, often, these CBOs lack capacity to effectively implement these programs and activities which affected collaborative efforts between them and their partners and this impacted on implementation. Also in Botswana, the different actors pursue interest and priorities such that the private-for-profit actors supplying infant formulas for mothers using PMTCT services, NGOs provided HIV testing services and specialised public facilities provide ART services. The implication for service users is that a mother living with HIV and AIDS had to use different facilities for ART, PMTCT and infant formula services making it difficult for mothers to access the service and for health providers to synchronise and monitor the services received by their clients. These examples demonstrate that collaborating actors and activities in programs designed to be vertically implemented is difficult to achieve.

Another important factor that influenced collaboration among actors was trust at the national levels and point of service delivery. The country cases revealed two main forms of trust issues: interpersonal (between healthcare providers and patients) and inter-organisational trust between actors. In Botswana, trust issues were commonly found to create gaps for poor patient-provider relationships that affected women's access to and utilization of available services, while creating problematic micro-practices contrary to the PMTCT policy. For instance, the inconsistent outcomes experienced by infants breastfeeding against those on formula had worsened this patientprovider relationship. A provider indicated that:

“...it is not easy to encourage an HIV-positive mother to breastfeed when you know that does pose a risk for her infant, no matter how small the risk is" (Health Provider: Botswana)

This lack of understanding created distrust in the health system. For some women who were encouraged to breastfeed they also attributed their children's HIV-positive status to this 'wrong advice' from healthcare providers, as one woman indicated:

"I could not understand how my child contracted the virus, I attended PMTCT and did all they asked, I do not know why they told me to breastfeed". (Service User: Botswana) 
Such instances affected women's attendance and utilization of available services but most importantly trust in the services and advice offered by health workers. The policy on infant feeding was selective because the guidelines required health workers to assess women based on the acceptable, feasible, affordable, sustainable and safe (AFASS) recommendation. But women themselves did not understand the differential recommendation with most socially disadvantaged women feeling discriminated against with their children put at risk of vertical transmission. The issue of interpersonal trust was further created by the different salary structures among healthcare workers. Those paid by government often earn less than their counterparts paid by donors and NGOs. This created tensions that also hindered collaboration and sharing of information.

In Ghana, lack of trust affected patient-provider relationship because patients perceived health workers to discriminate against scheme members and treat them badly as compared to those paying out of pocket. Similarly, they perceived the quality of care to be lower under the NHIS because of the use of generic drugs. This lack of trust for health services and between patients and providers led to the general perception that services under the NHIS is poor therefore not responsive to their needs. Also, health providers and scheme managers constantly battled with trust issues in terms of claims for services provided to member considering the weak capacity of scheme managers to vet those claims or monitor health services provided to their clients. Delays in claims have led health providers to charge for prescriptions, laboratory and other services meant to be free, contrary to the benefit package and government aim to improve access to healthcare.

In Malawi, the lack of HIV/AIDS financial information from the Ministry of Health (MoH) and Department of HIV and AIDS in the Office of the President and Cabinet led to concerns about accountability and monitoring of resources within the government system and among the non-governmental organizations (NGOs). While the government also wanted NGOs to account for all the funds they received from external donors the government's own lack of trust and transparency led to the withdrawal of some global funds critical for the implementation of the HIV and AIDS program (see Governance). From these country cases, the impact of establishing trust beyond organisational boundaries was critical towards achieving collaboration and policy outcomes. In Ghana and Malawi, lack of trust among national level actors resulted from the lack of information, transparency and collaboration between the oversight institution and supporting actors creating gaps in partnership formation, funding and support for service providers.

Positively, donor agencies that provided funding and created mechanisms to establish trust between themselves and other actors. DANIDA gained a lot of trust among actors in study districts in Ghana because of their prolonged engagements with them, provision of resources and technical guidance during the initial implementation of the NHIS. This made them powerful in negotiating access to information and influencing district and national level actors. Similarly, in Malawi, the NGOs dealing with HIV and AIDS services before the national policies was implemented also maintained a lot trust in their ability to support patients and communities dealing with HIV and AIDs which is important for service provision and collaboration. Also, they have collaboration as part of funding conditions between the NAC and NGOs in Malawi among multiple NGOs to enable complement HIV \& AIDS services. While in Botswana, PEPFAR remained the most pivotal and widely accepted partner providing technical and financial assistance toward the fight against HIV and AIDS. Most PEPFAR funded activities and personnel seconded at National and local levels were highly integrated into the government structures, even though tensions remained especially around issues of data collection, management and information sharing.

On another positive note in both Ghana and Malawi, community leaders played a significant role in the planning, implementation and resource allocation during policy processes. Traditional and religious leaders, heads of selected institutions including NGOs and civil societies developed partnerships for improved access to programs, and addressed key problems of utilisation and lack of resources in order to improve service user's experience. In Malawi, community leaders' oversight role at governing boards and committees was itself a significant platform for participating in policy processes. They engage in decision of NGOs and present community needs and how best they should be implemented. Similarly, reports made by the district schemes showed how instrumental some community leaders serving of the governing board of the District Mutual Health Insurance Schemes could be. In some cases, at the national level, NGOs, donor agencies and the government effectively collaborate through technical working groups and monthly district meetings. In the districts in Ghana specifically, community leaders partnered with scheme providers to make joint decisions about enrolment criteria, shared resources and improve enrolment onto the NHIS. For instance, the change from mandatory household registration created an opportunity for women and children to enrol onto the NHIS as a unit instead of the entire household as prescribed by the policy. Also with the 
collaborative effort of community leaders and institutions, the district schemes shared resources from the local government to enable them to promote their outreach programs or mobilise community members to engage in durbars and other outreach programs.

The cases demonstrate that collaboration cannot be taken for granted in implementation because of the significant gap it creates between planned policies and outcomes. Collaboration overall involves the participation, roles and functions of multiple actors in national policies such as these and how they are managed through implementation strategies, communication, access to information and policy knowledge, and negotiating actor's relative power, influence and trust. This process requires constant negotiation for joint actions, exchange of resources and information while working with units and sectors internal and external to the actors' own organisations. Yet, the process is often challenged due to the complex range of relationships, needs, interest, power as well as competition over resources affecting policy outcomes (discussed elsewhere). All of these also demonstrate how difficult it is to coordinate vertical program and service often led by African countries.

\section{Discretionary power:}

Discretionary power is another critical factor that create a gap between health policies and implementation because it directly influences how services are experienced by the public through the action and inaction of frontline workers. Frontline workers exercise their judgements and power on how services are delivered when eventually operationalising policies and programmes, sometimes in opposition to the rules and guidelines set out by the policies with detrimental consequences to service users as reflected in the statements below by this health worker in Botswana.

We are aware that women have various challenges when they come for ANC, and they should be provided with any possible advice and referred to social workers when necessary. The problem is that for us we really can't provide guidance and counselling when you have many other women waiting outside. I mean we try, but how much of it we can do is limited. This is why we encourage women to attend the morning health education sessions, because that is where women have the opportunity to ask questions. (Health Provider: Botswana)

Frontline workers have demonstrated this power by using their discretion to respond to client needs differently, influence services provided, interpret and re-interpret policies or apply those policies based on their personal values, worldviews, experiences and mindsets, and ration services based on resources availability. For instance, rescheduling services suitable to the working demands of health workers as described above is a typical expression of their power and how this impact on availability of services.

In the three cases service providers demonstrated how underlying factors such as their personal values, worldview and mind-sets influence service provision. These shape their interactions with clients as well as how services are accessed or delivered. In a typical example during the implementation of the NHIS in Ghana, healthcare practitioners were judging service users based on their ability to pay during medical consultation.

“... Sometimes you compare the kind of medication you give to the clients... once I told a patient, I could have written this drug for you but once you do not have insurance, if I prescribe it, you can't pay....” (Healthcare Provider: Ghana).

Similarly, in Malawi, the judgement by providers' on when to initiate ART to clients and the protocols prescribed create differences in the quality of care received by each service user. For instance, most patients in private-forprofit facilities were put on ART earlier than those in the government hospitals. Often, the clients were not offered an HIV test preventing them from knowing their HIV status in time. The implication of such judgements is that it undermines the needs of service users with each patient experiencing healthcare differently to the point where others are excluded from accessing the service.

In Botswana, a service user described how as a client the quality of service they receive was influenced by the providers' judgement of them as complaint or not to antenatal care protocols.

"You better have an ANC obstetric booklet showing that you have been attending ANC ....They (healthcare providers) will not help you if you do not attend ANC when you are still pregnant and you just come when you are having the baby. I was afraid of them." (Service User: Botswana) 
Health providers' perceptions of service provision during implementation of health programs, such as the antiretroviral therapy (ART), PMTCT services during antenatal care and health insurance provision, have implications for service users' experience, and create differences in the quality of care received by each service user. Providers' judgement of service users' ability to comply or not to antenatal care protocols determine the quality of care received in Botswana. In Malawi, patients' ability to access ART in private-for-profit facilities led to earlier diagnosis and intervention than those in the government hospitals. The pressure of work on health providers in the public facilities sometimes led patients to wait longer at the health facilities, those that could not be seen by a health worker returned home and came back when their health condition had worsened. This is a common occurrence in many of the public hospital where there are often long waiting times and deterring patients from attending these facilities unless they are dying.

Frontline workers also exercised discretionary powers through the rationing of services, using self-imposed rules and restricted working times, rationing of resources and information available to clients and other colleagues. Although the health programs were aimed at promoting access to care, service users in all three cases reported being refused healthcare, penalised or reprimanded for arriving at the health facility 'late' to access non-emergency services. Whereas some patients were asked to report back for service earlier the next day or another day, others were told to use alternative sources for their emergency services, drugs and laboratory needs making it impossible for them utilise the services due them.

For service users, the rationing is to compel compliance with the rules set out by providers. But for providers it is determined by the forces of high demand, limited resources and providers' attempts to create routines to manage the conditions of their work environment. Irrespective of the rationale for it, rationing of services meant to promote equitable access to health rather than exclude patients who need these services.

"Ah! The first time I went to register I think I was three months [pregnant], and the nurse there told me to come back the following day, saying 'How can you come at this time?' She did not even ask me why I came at that time, just said that I should come tomorrow...." (Service User: Botswana)

"If you go to the facility in the morning, it is easier ... but people wait till late before attending the facilities, which is not the best because it makes the nurses angry and they complain or abuse you... and sometimes send you back home". (Service User: Ghana)

"We prefer not to mix them (HIV/AIDS patients) with our regular clients ... because they do not want to be seen for the sake of privacy so we give them different days to report" (Private Provider: Malawi)

However, the policy in Malawi requires that the services should be provided every day and throughout the day. These scenarios demonstrate how decisions made based on providers' context, values and judgements of their clients become a critical part of their ability to act and respond to different client needs [48], but also how they respond to policies within the reality of their working contexts. This also demonstrates that great policies by themselves do not achieve equitable healthcare access, but the resources and actors' ability to align their action to the aim of these policies are important for policy outcome. Yet, it is difficult to achieve this because of the challenging condition within which health workers function. For the women in Botswana, it implies that those that cannot make it in the morning cannot access the services which might mean continued transmission of HIV from mother to child despite having a PMTCT programme in place.

"Really, I cannot say there is a scientific basis to it, it is really a situation brought on by the difficulty of a shortage of staff. Like as head of unit you know later in the day you'll get caught up in other activities, including meetings, especially here at clinics, and sometimes you will be alone ...." (Health Provider: Botswana)

The rationing of these services is not based on the policy requirement, but the forces of high demands, limited resources and providers attempt to create routines to adapt to the conditions of their work environment. A health worker in Botswana reflected on this when asked to comment on women's argument that they are required to attend ANC in the morning even though the official closing time for the clinics were 4:30 pm, she explained:

"... they are encouraged to come early to allow for specimen collection and the [turnaround for] results, which the laboratory technicians must also enter into the system, so it takes time". (Health Provider: Botswana). 
Similar circumstances allowed frontline workers to re-create and re-interpret policies, such that service users in Ghana are required to privately purchase prescriptions under the NHIS when reimbursements from the schemes are delayed, as an adaptive strategy to managing lack of resources and funds but also interpreted as curbing "abuse of resources by scheme members'. Whereas frontline workers in Malawi provide ART services on specific days of the week due to staff workloads despite the full integrated health service policy, and nurses in MCH clinics in Botswana strictly reserve the afternoons for outreach programs, which they were not always able to conduct during busy hours due to limited staffing (see Resources).

These myriads of factors demonstrate the complexities that frontline workers deal with routinely and how embedded they are to their practice, affect service provision and implementation. The power and influence of frontline workers means that policies are implemented only when they put them into practice to suit the complexity of their day-to-day work. Frontline workers, whether as service providers or implementers, are influential and powerful because of their ability and authority to impact on service provision. Their exercise of discretionary power whether directly or indirectly have consequences that transcend beyond service provision to processes, actions of other related actors and policies [22]. The use of discretionary power was pronounced in cases where frontline workers were constrained in one way or the other as workers, hence the need to contextually operationalise the policies.

\section{Resources:}

Resources were reported to be a constraint at all levels, experienced by implementers, frontline workers, leaders and managers, and service users. Lack of resources is one of the underlying factors influencing all the other factors. This invariably contributes toward implementation gaps because they have the potential to alter services, policy process and how actors deal with implementation and programs. In all the country cases, the lack of organisational and personal resources created pressure for which service providers had to adopt coping behaviours to manage high demands and time pressures.

“... Yes, the patients are coming more... and the equipments are the same, I actually haven't seen any new ones... occasionally we get some new ones being added to it, so it is actually having an impact on the in-patient care." (Regional Director: Ghana)

Also in Botswana, in spite of the various efforts to ensure adequate coverage of the PMTCT, resource constraints was one of the major setbacks for the programme. It was advisable for women to attend ANC early in their pregnancy, i.e. the first trimester but the "women had gone to (some) clinics to register but had found no nurse or midwife available, and nobody else able to assist them" $(39, \mathrm{p} .241)$

Health providers work in contexts of infrastructural, financial, logistical and technical constraints further compounded by the various social factors such as culture and religious values. The constraining environments as demonstrated earlier impacted frontline workers' ability and power to function. On the other hand, it affects the services accessed, offered and experienced by service users. For instance:

"Availability of drugs is a problem to scheme members... because of the increase, we run out of drugs so members are turned away sometimes when the drugs are not available.... And this is due to the increase in facility visits which the hospital cannot keep up with and the intricate process of stocking up depends on the available drugs at the district medical stores.... "(Healthcare Provider: Ghana)

In government health facilities, the number of health workers are too few to provide good quality of care. Despite the high numbers of patients requiring HIV services in Botswana, there were no special health workers fully dedicated to HIV services nor special rooms for HIV patients because the services were fully integrated. Although this is a good system, sometimes this poses challenges for staff capacity and space for privacy.

For service users and frontline workers, these constraining environments created gaps between the policy intentions or program aims and clients experience during service provision. Working with limited resources compelled the exercise of discretionary power to accommodate these challenges as demonstrated earlier (see Discretionary Power). The limited numbers of healthcare workers at the facilities had detrimental impact on access to the quality and timeliness of services rendered to service users in all cases. 
The lack of resources at the national level also created a gap in achieving implementation outcome. For instance, the National Health Insurance Authority and Ghana Health Service lacked the need expertise and technology vet claims, monitor quality of care and ensure services reach their clients across districts (see Governance). In the Malawian and Botswana cases, most participants reported resource constraints relating to limited numbers of healthcare workers to effectively support the demands at the facility levels. Meanwhile, to offset the pressure at the public facilities, private providers were recruited to provide ART services.

The lack of resources and skilled personnel contributed to the pressured environments within which frontline workers operated, which in most cases directly or indirectly impacted on their attitude towards service users. Results pointing to poor attitudes of health workers were reported in all three cases. Health workers were perceived as short tempered, intolerant, unsympathetic to clients' needs, irritated and sometimes vindictive towards those 'not following instructions'. Health workers were simply perceived as unresponsive. Provider-patient relationships were sometimes very strained because patients experienced long waiting times, poor attitude of health workers, inefficiencies of services and poor communication. These had detrimental impact on the services that users were able to receive when they needed them, as well as the quality of care they received as indicated by some service users in Botswana and Ghana.

“Well once you've tested HIV-negative they don't tell you anything anymore. They don't tell you anything about preventing the virus from infecting the baby, they just leave you alone, so I was not enrolled in the program for preventing the virus from going to the child because I was HIV-negative. When I came for the six weeks [post-natal care] check-up I was not tested either, even my baby was not tested." (Service User: Botswana)

"Because of the increase in attendance, there has been pressure on health workers, they get tired and agitated [and make] silly mistakes. They show a very rude attitude to us, especially when you make mistakes or ask too many questions about how to do or find things.” (Service User: Ghana)

Also, the lack of resources affected communication and collaboration among actors providing governance, management and leadership functions at the national and district levels. At the national level, lack of resources mandated joint actions and shared resources between the ministries, implementing and donor agencies predominantly operationalising and funding these policies respectively. At the districts, health managers and some NGOs lacked resources and had to work jointly in the case of Botswana and Malawi and in Ghana this was reported between the community leaders and scheme managers who lacked the resources to function routinely (see Governance).

Despite clear policies and contextual differences between country cases, the need to cope with the constraining environment amid limited skills affected implementers and policy recipients in different ways, creating a gap between policy and outcomes. Dealing with these constraints affected frontline workers' values and worldviews, and how they responded to clients and policy changes. Clearly, it also had an impact on the quality of service in terms of user experience and satisfaction. Improved health outcomes are measured by quality of healthcare provision, which according to the WHO (2006) should seek to be effective, efficient, accessible, equitable, acceptable or patient-centred and safe [49]. The staff and resource constraints do not only impede quality of care and frontline workers' attitudes among other things, but also contribute to low output, efficiency and performance. Resource constraint is predominant to problematic implementation of health policies. It was reported across all factors and it is the underlying factor making health workers unresponsive to service users needs as well as to collaborate to maximise resource use and implementation.

\section{Governance:}

Governance is conceptualized as addressing the political and technocratic dimensions of implementation. Governance was expressed in the cases through various elements such as management, leadership and political influence, policy framework, monitoring and supervision during implementation. The ineffectiveness of these elements created gaps between the policy prescription and actual implementation. In all three cases for instance, leadership and governance directly determine how actors' relationships are managed, decision making and resource control. The effectiveness of governance was expressed through the leaders' ability to collaborate or manage the implementation of the policies (see Collaboration). However, what is interesting and critical to note is how these governance elements were influenced by political will and commitments at the national level, interferences from national actors and resource allocation management. 
Across the three cases, mandated government authorities such as the National Health Insurance Authority (NHIA) in Ghana, National AIDs Commission (NAC) in Malawi and the Department of HIV and AIDS Prevention and Care of the Ministry of Health $(\mathrm{MoH})$ as well as NACA in Botswana had oversight responsibility and leadership for the respective implementation (see Table 1). For instance, in Ghana, the NHIA (then National Health Insurance Council (NHIC), was created in 2004 as an agency of the MoH with the mandate to provide leadership guiding the identification and creation of the structures and functions needed to operationalize the NHIS. Malawi also established its National AIDS Commission in 2001 as an agency as an agency in close coordination with the Ministry of Health with the mandate to provide overall direction and harmonization of Malawi's HIV and AIDS interventions. Botswana's PMTCT program led by the Department of HIV and AIDS Prevention and Care of the Ministry of Health working closely with other ministries and government agencies, NGOs, private entities and donors to provide HIV and AIDS services. These national level authorities have specialised mandates to direct the programs and actively correspond with other agencies for implementation. They also represent the government's commitments to support the policies and programs, provide and regulate their resources and align their activities to national plans. As a result, their activities tend to be influenced by politics.

Political influence is another dominant element of governance recorded in all cases. National politics and direct government influence were predominant during implementation at the national levels in Ghana, Botswana and Malawi. Therefore, the leadership of each of these implementing agencies is politically determined. In Ghana, the NHIS was a critical part of the political manifesto of the ruling party (the New Patriotic Party) leading to its implementation in 2001. Therefore, the political will to implement the policy was strong and the government played a critical role in determining the executive secretary to drive implementation. This was so important that three executive secretaries were changed between 2004 and 2008.

Similarly, in Botswana, considerable political commitment from the Office of the President, led the 3rd President to champion the universal access to HIV/AIDS prevention, care and treatment, and prioritised prevention. The PMTCT was launched in Botswana's public health system at a time when many other developing countries were still debating its feasibility. Although political will was also there in the Malawi ART programme, the country also experienced some political interference in the management of the NAC by appointing politically inclined candidates into the position of NAC director, who then facilitated the diversion of HIV and AIDS resources to other non-HIV related activities at the directives of top political figures. To surmount some of these political interferences the external funds for purchasing antiretroviral drugs are not directly managed by the Malawi government. Instead the donor pays directly to the supplier after getting orders from the Malawian government and use of other channels such as NGOs. For instance, in 2015 Reuters reported that the Global Fund cancelled its HIV and AIDS funding to Malawi due to mismanagement.

“The Fund has asked us to repay $\$ 6.4$ million for buying vehicles which were not budgeted for and they have also pulled the plug on $\$ 574$ million funding for the next two years because of allegations of financial mismanagement and political abuse," (Minister of Health: Malawi Reuters News).

In a later news report, the Minister of Health confirmed that Global Fund was planning to channel its HIV and AIDS funding through other organizations rather than the NAC. Earlier 2015, there were protest from some activist petitioning the Global Fund from channeling HIV and AIDS funding through NAC after it had given away 33,000 USD to organizations with close ties to the President and his wife. This is what one of the activist had to say on the matter:

“...clearly NAC was diverting funds meant for putting people on anti-retroviral drugs and giving it out to political organisations who have nothing to do with core-anti Aids activities," (Health and Political Activist, Malawi).

The implication of such political influence has been both enabling and constraining therefore boosting and deterring it at the same time. Specifically, in Ghana, it led to increased organisational tension among implementing actors, abrupt change in strategic leadership at the NHIA, trust and power issues, and conflict/tension among actors which constrained implementation. Thus, instead of reporting to the $\mathrm{MoH}$ and Ministry of Finance and Economic Planning (MOFEP), the NHIA was reporting directly to the Office of the President and taking decision and without consulting these primary ministries. 
... Although the NHIC is supposed to be reporting frequently to the $\mathrm{MoH}$, the administrative and executive team members took decisions, and implemented them without consulting or informing the $\mathrm{MoH}$.... There is a conflict between the Executive Secretary and the chairman of the Council [as well] .... These private consultants are working without any official contracts made, background check, and this formed the main source of conflict within the central institutions of the scheme such as between MoH and NHIC." (MoH: Ghana)

The political influence led to conflicting and multiple directives from NHIA to key actors at the national and district schemes. This led to reported cases of frustration among scheme managers on what/whose directives to use in guiding specific activities or addressing problems affecting them.

"Inconsistency at the national level is affecting us at the district. For instance, the conflicting instructions on the type of software to use for the scheme's card make it difficult to choose the right one. Conflicting orders from the council on which institutions to correspond with and accept logistics from has all confused us .... There is no format for reporting to the Council, they do not give clear directives on what data are needed so the schemes have not captured such data during registration, and we are doing what we did before...." (Scheme Manager: Ghana)

The situation was similar in Malawi, where the NAC report to the Office of the President and Cabinet (OPC), Ministry of Health (MoH), Ministries of Finance and Economic Planning and Development, Department of Human Resources Development and Management, the Law Commission and the Human Rights Commission with priorities given to the office of the President and Cabinet. The effect of these multiple lines of authority is that the most powerful office is given priority due to their control over funding and policy regulation. The political and organizational agenda being prioritized often undermine the aim of the policies and programs as expressed by the scheme manager above.

However, it also enabled implementation as the needed financial resources and leadership supports were given. Using political leaders to promote these programs was reported across the cases. In Botswana, the President championed the fights against HIV/AIDS and by extension PMTCT program as one of the key strategies. Hence, the need to report to the Office of the President. In Ghana, national politics were used to drive publicity, and political leaders who had campaigned for the NHIS paid for some party members to enrol when it was launched in some rural areas. Even though the political associations towards the NHIS still lingered on, its impact has lessened since the change of government in 2008, indicating the dynamics of power and politics and their impact on implementation.

Another critical governance element is the availability and access to policy framework guiding implementation and its alignment to resources, structures and the context. In Malawi, the National HIV and AIDS Action Framework (NAF) stipulates the main priority areas for HIV/AIDS interventions and some specific components to respond to the special needs such as the National HIV Prevention Strategy; Prevention of Mother to Child Transmission (PMTCT) roll out plan; ART scale up plan; National Impact Mitigation Strategy; and national plan of action [42]. The National Health Insurance Act, 2012 (Act852), (then the NHIA 2003 (Act 650) [41] and its Legislative Instrument, the National Health Insurance Policy Framework and other relevant documents provided the policy framework for the NHIS in Ghana. The Botswana National Policy on HIV and AIDs (2012) stipulates the short and medium-term plans and government strategies to strengthen multi-sectoral action and local response to HIV and AIDS. These policy frameworks outline both the national strategies and implementation guidelines [50].

At the facilities, these policies were described by actors as being too broad, narrow, complex, or having vague impact on their operations because they were subject to various interpretations and often provided little or no practical solution for implementation and its challenges.

This was expressed in all cases and summarised in the experience from Botswana where implementation of the universal ART and specifically PMTCT $(2009$ - 2012) was especially fraught with numerous challenges owing to the complexity of the protocol/guidelines the problem of addressing unintended consequences from the program. For instance, HIV-positive mothers at one point were to be given formula milk to replace breastfeeding, but this was later revised when diarrhea and multi-nutrition became prevalent - at a workshop for healthcare workers this issue was discussed extensively, with most healthcare providers indicating 'it is not easy to encourage an HIV-positive mother to breastfeed when you know that does pose a risk for her infant, no matter how small the risk is'. 
In all the cases, most part of the policies and frameworks were not accessible to frontline workers or their managers, but priority areas are communicated through directives. In Ghana, operationalising some of the NHIS policies such as the gatekeeper system, exemption policies, routine accreditation for health facilities and providers and household registration per the policy prescription was difficult, either because the policy was too vague or they lacked structures and resources to support them. This facility manager expressed the challenges associated with implementing the gatekeeper system below:

"In most medical cases, we know what to do but we don't have the powers to do them, prescribe or even manage the condition, so we refer the person to Nkoranza [a district hospital] ... and it is making them [the community] lose confidence in us, people are now saying that instead of wasting their time at the rural clinic they would rather go to Nkoranza since they will be referred anyway..." (Health Provider: Ghana)

The discrepancies between policies and implementation is much more evident in how actors perceive, experience or interact with policy frameworks guiding their work. In Botswana, there was not any clear operationalisation of patients' lost to follow-ups, adherence and defaulting to guide the practices of healthcare workers. The inability to adequately operationalise policy content is another major contributor to implementation gap, which must be acknowledged by policy makers and implementers. For instance, when HIV/AIDS programs were integrated into maternal and child health services in Botswana, particularly HIV testing, clients were not always made to understand the process of opt-out - that they do not have to take an HIV test to receive the services they have come for. This was echoed by most women who attended antenatal care:

"Yes, I took an HIV test. Isn't it that when you register the nurse will tell you that you have to do an HIV test? That is why the first thing they do before they give you a booklet is give you a slip to go to the caravan where you do urine and blood tests, because they have to do an HIV test so that if you are sick you can be given medicine to protect the baby. (Service User: Botswana)

The implication on implementation is that frontline workers often lack the holistic perspective and strategies defined by the policy frameworks. Also, these frameworks were perceived to be inaccessible in supporting and addressing their day-to-day operational challenges as captured above. In Malawi, there were also some confusion in the use of guidelines for initiating ART where different doctors interpreted the guidelines differently. The Malawian research found that clinical staging procedures were marred with because the process was quite subjective based on the medical conditions of the patients and the doctor's judgement. Yet these medical conditions change dramatically within a short period of time and there seemed to be no clear relationship between clinical staging and CD4 count assessment criteria as set out in the clinical guidelines. This kind of diagnosis would imply a delayed start of ART in some patients, or no start at all for others whose illness might progress quickly to death.

Supervision and monitoring is another critical element of governance that ensure compliance, quality assurance, accountability and identification of potential gaps. The cases revealed two forms of monitoring; organisational level monitoring usually common among health providers and facilities and the monitoring of patients with chronic diseases such as HIV/AIDS. The most commonly reported form of organisational monitoring is to ensure quality assurance using mechanisms such as accreditation, client and staff satisfaction surveys, complaints procedures and routine reports, vetting of claims (in the case of the NHIS in Ghana), and adhoc audits or self-reported audits, routine supervision and management appraisals. The organisations and providers responsible for monitoring, evaluation and supervision reported how these strategies were sometimes ineffective.

"The facilities report to the Coordinators on what is happening... when Coordinators are resourced they also visit those facilities. But I know they don't have that much [money] to do so many visits. In the beginning, a lot of work was done, the work had been training and orientation, education and all of that. But M\&E [Monitoring and Evaluation] hasn't been [undertaken very] much when they go on their routine visit from the regional office so they add some of these things to the monitoring process" .... " (Policy Implementer: Ghana)

At the organisational levels, limited supervision on service provision, resource allocation and application of policy guidelines during implementation of programs had resulted from the lack of enforcement. The capacity to monitor and ensure routine supervision is challenged as a result of poor data capturing processes creating a gap for evidence to support implementation. In all cases supervision and quality assurance was based on self-reported processes initiated at the facilities by the providers themselves or by standardised tools. In instances of weak leadership and 
lack of resources, monitoring and supervisory tools only served as checklists. In some cases, where the oversight institutions were unable or failed to regularly monitor, supervise and ensure quality assurance, standardised tools, self-reported mechanisms and routine reporting served the purpose for control and supervision with very limited opportunities for feedback.

Lack of monitoring impact on service provision in terms of quality, access and responsiveness. In Botswana even though service users attended antenatal care services some of them were not re-tested. This lack of systematic follow-up of women and their children who initially test negative represented critical missed opportunities that hampered the effectiveness of the program because of the potential risk of seroconversion, where often late HIV diagnosis was prevalent among infants.

In another example, the NHIA in Ghana had the authority but lacked the resources and capacity to enforce effective monitoring and quality assurance. The provision of quality healthcare and services are essential for the sustainability of the NHIS, and having to rely on the Ghana Health Service's internal audit and monitoring mechanism for the public facilities had not always been effective to the Scheme's needs to quality services to their clients. Preferential and routine accreditation of the public health sector as compared to the rigorous processes undertaken by the private sectors created unequal opportunity for supervision and quality control. Similarly, in Botswana, providers lacked the human and financial resource to monitor the PMTCT programme protocol that details critical pathways through which issues of loss-to-follow up, defaulting and adherence could be determined.

In Malawi the HIV and AIDS Unit, a department within the MoH responsible for monitoring the ART programme had developed monitoring tools that include quarterly monitoring visits to all clinics in Malawi to collect data on patient outcomes and new registrations. As such the department always has up to date and timely data at its disposal for decision making. Those clinics that had up to date records were given awards for the good performance to act as incentives. However, there was little attention paid to checking the quality of data as was revealed in the ART data that had a lot of information missing despite the quarterly monitoring visits. These visits merely concentrated on collecting numbers rather than supporting providers to provide better services and this is a missed opportunity.

Monitoring, supervision and quality assurance, although critical aspects , are difficult to achieve, therefore creating a gap for evidence and performance indicators to influence implementation. The gaps affect quality of health services, provision of feedback and benchmark for process of implementation and has been limited to seeking information about achieving national/donor targets and routine data collection. The absence of supportive supervision in all the cases eliminated the opportunity to identify gaps, build personal and organisational capacities or explore innovative ways of achieving the policy outcome.

The range of governance elements influencing implementation is wide ranging from leadership, management and political influence to monitoring, supervision and policy framework. These impact on service provision, quality of care, evidence-based feedback with implications for resource allocation and collaboration critical for policy outcomes.

\section{Socio-Cultural Appropriateness:}

Another factor that creates implementation gap is the policy and programs sensitivity to different ethnic, sociocultural, educational and economic groups and an awareness of how these different backgrounds will affect community health needs and ability to access health services. At the community levels, the socio-cultural appropriateness of the policy determined acceptability and participation in it. In Botswana, the cultural impact of managing pregnancies impacted on adherence to $\mathrm{MCH}$ practices per the PMTCT guidelines. The biggest contention was that biomedical and traditional medicine was built on different explanations, so the expectations and practices of the community differed in this regard. Although legislation was passed to recognize traditional medicine practices, that did not impact on service users' behaviour and response to the PMTCT policies. Similarly, in Ghana, the sociocultural frameworks conflicted with practices such as household registration and exemption for the indigents, as what constituted those definitions in policy were contrary to their traditional practices. In the Malawian case, some HIV patients avoided ART services for the fear of stigmatisation and the belief that HIV is caused by witchcraft therefore, requiring spiritual and religious solution rather than ART. The context which might include people's culture, values and worldview impact on policy implementation and may prevent people from participating in the programs. This impact on how the communities interact with services and programs, understand the policies and accept its aims. 
Effective communication that is culturally appropriate for the communities and service users to enable them gain knowledge, understanding and engage with the policies was also constrained. In all the cases, directives, policy change and information were communicated in English language predominantly among the implementers. Service users or community members were excluded from the programs. This also impacted on their access to information vital to enable them to engage with the programs and services. This created a gap of how communities responded to policies and adapted health services to their socio-cultural and religious needs or gain awareness to inform decisions around access to healthcare. At the individual level, service users lacked information on the range of facilities that provided ART services in Malawi, or benefit packages available to Scheme members in Ghana for instance. They were disempowered from participating meaningfully during implementation. Although, service users have the responsibility to co-produce and demand quality healthcare. This is constrained by lack of information and knowledge about the programs. It was acknowledged that service users have critical roles and responsibilities in identifying their own needs and preferences [49], and in managing their own health, with appropriate support from health-service providers, but power dynamics and lack of information prevented them from adequately achieving that.

The role or involvement of service users as community members, patients or groups in health policies and program implementation is very crucial yet often ignored. Service users' experience of policies and programs are determined by their involvement in the planning, implementation, ability to ensure quality, availability of and accessibility to services, tailored health interventions into cultural and community needs. But in all the cases, community involvement was largely limited to passive service usage creating gaps in adapting the policies they need. Service users were not empowered as individual patients to seek quality care and access to services from care providers and programs implementers. As explained earlier, service users lack the power and ability to seek explanations for the level of services they receive or not, or adapt services to their needs.

From the findings, it is evident that the gaps in policy implementation are multifaceted including coordination, discretionary power, resources, governance and socio-cultural appropriateness of the policies. Yet, these factors are extremely interlinked and complex requiring a systems approach to understand and analysing their impact on implementation and policy outcomes as well as explain how complex the gaps are.

\section{Discussion:-}

The findings from the reanalysis of the three case studies highlight a number of issues that policy actors need to pay attention to when implementing policies. These includes issues of collaboration, resources, provider discretionary power, governance and socio-cultural contexts. These results are consistent with other findings on implementation of health policies where they have found similar issues affecting implementation [31, 51, 52]. It is clear from the findings that the factors affecting implementation are highly interlinked requiring a systems thinking approach to unpack and address these gaps. De Savigny and Adam (2009) state that systems thinking requires a "deeper understanding of the linkages, relationships, interactions and behaviors among the elements that characterize the entire system" and that all health interventions are embedded in some systems and therefore have system level effects linked to some of the health system's building blocks [53:33]. This study findings are very much centered at people affecting various aspects of the implementation process.

For instance, collaboration is all about various groups of people and individuals working together to fulfil certain tasks. Similarly, when we talk about discretionary power, we are focusing on individuals charged with responsibilities of implementing the policy who use their discretionary power to provide the services depending on several factors that include resources availability, their personal or/and organizational values, beliefs, perceptions, knowledge, experiences, ideas, interests and other contextual factors. These very factors are what enable or hinder collaboration among actors for effective implementation of policies. Gilson et al (2006) in their four case studies conducted in South Africa, Tanzania and Zambia on health-equity related implementation gap also found out that although equity goals are, generally, supported by health workers and local managers, policy resistance can arise from the divergence "between their understanding of their job requirements their roles in the health system and specific equity-promoting policies." They therefore recommend the need for implementation strategies to pay attention to these actors" interests by "actively working with their worldviews" by "either demonstrating how policies are aligned with these worldviews or encouraging the adaptation of their worldviews" [31:16]. This is a very important consideration if policy implementation gaps are to be addressed. 
This closely relates to the idea of communication and knowledge sharing among all the actors along the lines of hierarchy including services users, which speaks to the notion of combining the top-down and bottom-up approaches to bridge the gap. This is to say that the policy need not be too prescriptive and authoritative in nature but rather provide the flexibility for the implementers to adopt and fit their context in the best possible manner that retains the policy goals.

Another aspect that came out of the findings of this study was the role of resources in the implementation process. Resources are at the core of implementation both financial, human resources, material/infrastructural, drugs, among others. As discussed in the findings, lack of resources in terms of number of health workers created implementation gaps which made the health workers to use their discretionary power on how to operationalize the policy requirements and provide the services including rationing or not being able to provide some services at all if they do not have the resources.

At the same time these resources are highly dependent on governance issues including political will to commit fair amounts of resources to programs. In the case studies presented, there seemed to have been good political will in terms of allocating financial resources in these programs which in part led to a relatively successful implementation of the policies but this needs to be sustained for long terms projects such as these. This finding was noted in one of the studies conducted in Mozambique, Senegal and Tanzania where the respondents indicated that local resources were more effective in implementation of long-term plans than relying on external sources [51]. Governance also entails accountability and transparency in the allocation of resources as well as supervision and oversight of the implementation process.

Considering that the actual measurement on whether the policy implementation is successful or not is measured on how well the intended beneficiaries used the services to impact on the policy goals. With this in mind, the sociocultural appropriateness and acceptability of the services to users came out as another important factor. With acceptability becoming a 'key consideration in the design, evaluation and implementation of healthcare interventions" $(37 ;$ p.1), it is imperative that policy makers and health workers understand its inherent complexity and find ways to especially include healthcare users in their quest to improve access and equity. When the intricate elements of these policy implementation factors are not entirely understood, they will only remain known but without the corresponding effect of adequately addressing them in order to shape and influence how they impact on policy implementation.

All this brings us back to our question why despite so much work and research that has been done in the past 4 decades we still have implementation gaps especially in Africa. One of the major reasons is that according to this analysis sub-Saharan African is caught up in seriously problems of poverty which increasingly add on the power relations dilemma between the health professionals and the patients whose rights are often not respected. As indicated by Simwaka (2008), patients are subjected to all sorts of treatment and have no voice to stand against those abuses. The end result is that many simply avoid the services due to lack of acceptability. This is also connected to the socio-cultural appropriateness of certain services and how they are delivered to the people. Sensitivity to such issues would entail a different approach to service delivery, firstly starting with education to the massed and securing their buy in before rolling out certain projects and this will be possible if more of the bottom up approaches are encourage in the policy process. Schofield also identified bureaucratic discretion, role of actors, knowledge, learning and capacity as well as policy processes as instrumental to policy implementation.

While most of these gaps in health policy could be improved upon, it has to be acknowledged that some these barriers calls for the multi-sectoral collaboration. Achieving the SDGs is one way through which some of these implementation gaps will be improved. Therefore, using systems thinking might be key in assisting health policy actors to approach the implementation issues in more holistic manner rather than in isolation. Many of the studies on implementation are fragmented in terms of the issues as stated by Erasmus et al (2014). This view is also supported by Saetren (2005) who indicate that there is fragmentation in terms of publication patterns whereby this subject is being published by too many different journals. This indicated a challenge towards the consolidation efforts on "systematic knowledge accumulation" in the field [6:567]. This paper is trying to contribute towards the consolidation of the various elements affecting implementation in health interventions.

Engaging systems thinking approach to policy implementation meant that policy makers and health providers recognize the complex and dynamic environment of health workers and that addressing implementation gaps 
requires more than a reaction to present outcomes and events. More importantly it is about understanding the key elements that give rise to complexity in the healthcare environment. The consequence of an action in one part of the system is completely different from its consequences on another part of the system, and that even well-intended actions can lead to unintended consequences. There are myriad contextual features that policy development and implementation must recognise and be optimally aligned with in order to yield better policy implementation outcomes. The linkages among these various features are not always a linear or straight forward one, they tend to be emergent with potential for unpredictable feedback loops, complex and dynamic.

This is because, the healthcare system is complex, consisting of both hard and software systems that interact in the most dynamic manner all the time. At the organisational level, the interaction between the hardware and software factors demonstrated the complexity of the health systems [56] in how the financial, human and logistical resources, governance and leadership, service provision as hardware factors were impacted more pronouncedly through their interaction with software issues such as trust, power, politics, values, culture and communications. Although most of these factors clearly demonstrate how policy intensions change during implementation practice, the complexity of the processes and the fuzziness of policies themselves makes implementation messier.

The reality of policy implementation is that it does not occur in a vacuum, but is embedded in context and often influenced, shaped, enabled or constrained by various contextual features [55, 57] in the health system, including internal and external organizational relationships, networks, actor engagements and resource availability. Health policies and programs are often viewed in isolation from the problems and policy goals and not as complex processes - with many embedded parts, roles and actors that are dependent on each other or have the capacity to affect one another both directly and indirectly. The challenges surrounding policy implementation in Ghana, Botswana and Malawi, as shown in this paper, point most significantly to the need for systems thinking when it comes to policy development and implementation. Meanwhile, the implementation strategies predominantly modelled after top-down approach regularly ignore frontline workers charged to implement the policies, with limited recognition and considerations for their buy-in and commitment, power to influence policy action, resource capacities and competencies to support policy action. From this multi-country experience, we argue that the gap between policy and implementation/outcome is embedded in the complexity of implementation, health policies and systems. It is this embeddedness that brings about complexity.

\section{Conclusion:-}

Knowledge and understanding of health policies at all levels, internal and external buy-in and the capacity to action the policy has proven critical to implementation. Factors such as political, social, cultural and economic context surrounding a particular policy, are usually difficult to predict and control, and therefore require constant negotiation to allow for the policy implementation process to succeed towards goals, including health care equity. Policy makers and decision-makers must be flexible and invest considerable amounts of efforts to work out, for instance, how power relations influence policy implementation, reforms and changes in service delivery, providers' roles and reallocation of resources. They need to come up with strategies for communication, negotiation and even bargaining among different actors as a way of governing the relationships that are created in the process of implementation. The roles of each actor and their related agents need to be clearly defined and managed to create shared values around a particular policy, especially where equity goals are being pursued. They must accommodate unintended consequences and the fact that policies are not lineally related to implementation outcome. Given the factors highlighted in the paper, it is important that policy makers and actors in LMICs rethink the process of making and implementing health policies, the process of engaging actors, monitoring and providing feedback loops and managing complexity for policy processes.

$\begin{array}{ll}\text { List Of Abbreviations: } \\ \text { AIDS } & \text { Acquired Immunodeficiency Syndrome } \\ \text { HIV } & \text { Human Immunodeficiency Virus } \\ \text { HPSR } & \text { Health Policy and Systems Research } \\ \text { LMIC } & \text { Low-and-Middle Income Country } \\ \text { MCH } & \text { Maternal and Child Health } \\ \text { MoH } & \text { Ministry of Health } \\ \text { NAC } & \text { National AIDS Commission } \\ \text { NGO } & \text { Non-Governmental Organisation } \\ \text { NHIA } & \text { National Health Insurance Authority }\end{array}$




$\begin{array}{ll}\text { NHIS } & \text { National Health Insurance } \\ \text { PMTCT } & \text { Prevention of Mother to Child Transmission } \\ \text { WHO } & \text { World Health Organisation }\end{array}$

\section{Declaration:}

Ethics approval and consent to participate:

This is article was crafted out of a thematic synthesis of 3 PhDs. It is in essence a qualitative secondary analysis and did not require human participation for the re-analysis of the existing data. However, ethical procedures were followed for the primary studies and duly acknowledge in the thesis. Please see the declaration for the sources to refer to the $\mathrm{PhD}$ thesis with embedded ethical measure.

\section{Consent for Publication:}

This manuscript does not contain any individual person's data in any form (including individual details, images or videos). Presentation of quotes in this article was given anonymous description of those who gave them. Informed consent was secured during the primary data collection (see reference nos. $15,16 \& 17$ for the full thesis).

\section{Competing Interests:}

I declare for myself and on behalf of my co-authors that there is no competing interest of financial and non-financial implication for this manuscript.

\section{Availability of data and material:}

The dataset(s) supporting the results of this article is (are) available in the University repositories as $\mathrm{PhD}$ thesis submitted by three of the authors (see reference numbers $15,16 \& 17$ with links to access them).

\section{Funding:}

Not applicable

\section{Authors' contributions:}

GT, DM, ML and BH all participated in the conceptualization of the topic, drafting of the manuscript and extraction of data (except for $\mathrm{BH}$ ), review and discussion of the data. GT, DM, ML and BH engaged in the literature scoping, abstract formation and presentation of initial ideas at the departmental workshop and discussions of findings from the thesis of GT, ML and DM. GT however, pulled the different sections together and through a coordinated effort with DM, ML and $\mathrm{BH}$, we reviewed the manuscript for submission. All authors read and approved the final manuscript.

\section{Acknowledgement:-}

The authors would like to acknowledge the mentorship and support of their supervisors Profs. Lucy Gilson and Uta Lehmann. 'The preparation of the paper benefitted from discussion at an April 2016 writing workshop organised by the Consortium for Health Systems Innovation and Analysis (CHESAI) to generate deeper Southern-led perspectives on health systems and governance issues, CHESAI is funded by a grant from the International Development Research Centre, Canada. We finally acknowledge the professional editor of the manuscript, Anna Strebel.

\section{References:-}

1. Calista D. Policy Implementation. In: Nagel S, editor. Encyclopedia of Policy Studies. New York: Marcel Dekker; 1994. p. 117-155

2. Love A. Implementation Evaluation. In: Wholey HHJS, editor. The Handbook of Practical Program Evaluation. San Francisco, CA: Jossey-Bass Inc; 2004. p. 63-97

3. Bhuyan A, Jorgensen A, Sharma S. Health Policy Initiative, Task Order, Taking the Pulse of Policy: The Policy Implementation Assessment Tool. Washington, DC: Futures Group;2010

4. Spratt K. Policy Implementation Barriers Analysis: Conceptual Framework and Pilot Test in Three Countries. Washington, DC: Futures Group, Health Policy Initiative, Task Order 1; 2009

5. Swanson, RC, Cattaneo A, Bradley E, Chunharas S, et al. Rethinking health systems strengthening: Key systems tools and strategies for transformational change. Health Policy and Planning, 2012, 27:iv54-iv61 https://doi:10.1093/heapol/czs090 
6. Saetren H. Facts and Myths about Research on Public Policy Implementation: Out-of-Fashion, Allegedly Dead, But Still Very Much Alive and Relevant. The Policy Studies Journal, 2005; 33 (4)

7. Béland D and Ridde V. Ideas and Policy Implementation: Understanding the Resistance against free health care in Africa. Global Health Governance, 2016; X (3).

8. Erasmus E, Orgill M, Shneider H and Gilson L. Mapping the existing body of health policy implementation research in lower income settings: what is covered and what are the gaps? Health Policy and Planning, 2014; 29 (Suppl. 3), iii35-iii50, https://doi.org/10.1093/heapol/czu063

9. Irani, L., K. Hardee, S. Welsh, M. Rodríguez, and M. Hamilton. Annotated Bibliography on Health Policy Implementation and Evaluation. Washington, DC: Futures Group, Health Policy Project. 2015.

10. Atkinson S, Medeiros RLR, Oliveira PHL and de Almeida RD. "Going Down to Local: Incorporating Social Organisation and Political Culture into Assessments of Decentralised Health Care." Social Science \& Medicine 2000; 51(4), 619-636.

11. McKenzie A, Sokpo E and Ager A. 2014. Bridging the policy-implementation gap in federal health systems: lessons from the Nigerian Experience. Journal of Public Health in Africa 2014; 5:38.1 doi:10.4081/jphia.2014:381

12. Simwaka LK. "How Power Relations Affect the Implementation of Policy on Equity in Access to AntiRetroviral Therapy: The Case of Rural Health Centres in Malawi." EQUINET Discussion Paper 69. Harare: Malawi Interfaith AIDS Association EQUINET. 2008.

13. Erasmus E and Gilson L. "How to Start Thinking about Investigating Power in the Organizational Settings of Policy Implementation." Health Policy and Planning 2008; 23(5): 361-368.

14. Lehman U, Gilson L. Actor interfaces and practices of power in a community health worker program: A South African experience of unintended consequences. Health Policy Plan. 2013; 28(4): 358-66

15. Balabanova D, McKee M, Mills A, Walt G and Haines A. "What Can Global Health Institutions Do to Help Strengthen Health Systems in Low Income Countries?" Health Research Policy and Systems 2010.; 8(22)

16. Behague DP and Storeng KT. "Collapsing the Vertical-Horizontal Divide: An Ethnographic Study of Evidencebased Policymaking in Maternal Health." American Journal of Public Health 2008; 98(4):644-649.

17. Brinkerhoff DW and Bossert TJ. Health Governance: Concepts, Experience, and Programming Options. Washington, DC: U.S. Agency for International Development; Health Systems 20/20, Policy Brief. 2008.

18. Walker L, Gilson L. 'We are bitter but we are satisfied': nurses as street-level bureaucrats in South Africa. Social Science and Medicine. 2004; 59: 1251-61

19. Sheikh K and Porter J. "Discursive Gaps in the Implementation of Public Health Policy Guidelines in India: The Case of HIV Testing." Social Science \& Medicine, 2010; 71: 2005e2013.

20. Haines A, Kuruvilla S and Borchert M. Bridging the implementation gap between knowledge and action for health. Policy and Practice: Theme papers. Bulletin of the World Health Organization 2004; 82:724-732.

21. Kebede D, Zielinski C, Mbondji PE, Piexoto M, Kouvividila W and Lusamba-Dikassa PS. The way forward narrowing the knowledge gap in sub-Saharan Africa to strengthen health systems. Journal of the Royal Society of Medicine; 2014, Vol. 107(1S) 10-12. DOI:10.1177/0141076813512818

22. In on Africa, IOA. Health systems research in Africa: Bridging the know-do gap between research and implementation (2013, March 18), Retrieved from http://www.polity.org.za/article/health-systems-research-inafrica-bridging-the-know-do-gap-between-research-and-implementation-2013-03-18 Accessed on 18.10.2017

23. Sanders D and Haines A. "Implementation Research Is Needed to Achieve International Health Goals." PLoS Med 2006; 3(6): e186.

24. Nakamura R, Smallwood F. The Politics of Policy Implementation. New York: St. Martin's; 1980.

25. Walt G, Gilson L. Reforming the health sector in developing countries: the central role of policy analysis. Health Policy Plan. 1994; 9 (4): 353-370.

26. Nilsen P. 2015. Making sense of implementation theories, models and frameworks. Implementation Science, 2015; 10:53. DOI 10.1186/s13012-015-0242-0.

27. Health Policy Initiative, Task Order 1. The Art of Moving from Policy to Action: Lessons Learned from the USAID Health Policy Initiative (2005-2010). Summary 2010, Washington DC: Futures Group, Health Policy

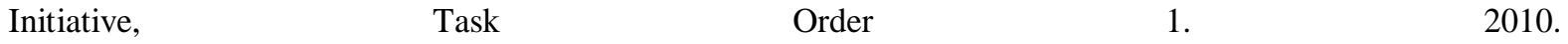
http://www.healthpolicyplus.com/archive/ns/pubs/hpi/1281_1_Art_of_Policy_to_Action_Brief_FINAL_Sept_2 010_acc.pdf 14.12.17

28. Peters DH, El-Saharty S, Siadat B, Janovsky K, Vujicic M. Improving health service delivery in developing countries: from evidence to action. Washington DC: The International Bank of Reconstruction and Development/ The World Bank; 2009 
29. Gilson L, Schneider H, Orgill M. Practice and power: A review of interpretive synthesis focused on the exercise of discretionary power in policy implementation by frontline providers and managers. Health Policy Plan. 2014; 29: iii51-iii69

30. Sabatier PA, Mazmanian DA. Policy Implementation. In: Nagel SS, editor. Encyclopedia of Policy Studies. New York: Marcel Dekker; 1983. p. 143-169

31. Gilson L, Erasmus E, Kamuzora P, Mathews V, Ngulube TJ, Scott V. Applying policy Analysis in Tackling Health-equity related implementation gap. Regional Network for Equity in Health in East and Southern Africa. 2006; Discussion Paper No. 28, p. 1-20

32. Barrett SM, Fudge C. Policy and Action: Essays on the Implementation of Public Policy. London: Methuen; 1981

33. Sturmberg JP, Martin CM. Handbook of systems and complexity in health. New York: Springer; 2013

34. Pope C, Robert G, Bate P, May AL, Gabbay J. Lost in translation: a multi-level case study of the metamorphosis of meanings and action in public sector organisational innovation. Public administration. 2006; 84: 59-79.

35. Elloker S, Olckers P, Gilson L, Lehmann U. Crises, routines and innovations: the complexities and possibilities of sub-district management. In: Padarath A, English E, editors. South African health review: Durban; 2012/2013. p. 161-173

36. Gilson L, Raphaely N. The terrain of health policy analysis in low and middle income countries: a review of published literature 1994-2007. Health Policy Plan. 2008; 23(5): 294-307.

37. Teddy G. From policy to process: An insider perspective of implementing the National Health Insurance Scheme (NHIS) at the Districts in Ghana. PhD (thesis), University of York, UK. 2009/2012. http://ethos.bl.uk/OrderDetails.do?uin=uk.bl.ethos.542808

38. Lembani M. Analysis of the effectiveness of Non-Governmental Organizations (NGOs) in HIV and AIDS Service Delivery: The case of Antiretroviral Therapy (ART) programme in Malawi. PhD (thesis) Institute of Development Research and Development Policy (IEE), Ruhr University Bochum. 2013. http://wwwbrs.ub.ruhr-uni-bochum.de/netahtml/HSS/Diss/LembaniMartina/diss.pdf

39. Molosiwa D. Trust and utilization of maternal and child health services in the context of HIV/AIDS in Palapye, Botswana. PhD (thesis), Australian National University, Canberra. 2013. https://researchers.anu.edu.au/researchers/carmichael-ga

40. Ministry of Health (MOH), The National Health Insurance Policy Framework: Revised Version. Accra: Ministry of Health, 2004.

41. National Health Insurance Act (NHIA), The Six Hundred and Fiftieth Act of the Parliament of the Republic of Ghana National Health Insurance Act, 2003, (NHIA 650). Accra, Assembly Press, 2003.

42. Malawi Government. Malawi HIV and AIDS Extended National Action Framework (NAF), 2010-2012 Draft; Lilongwe, 2009.

43. Weed M. A potential method for the interpretive synthesis of qualitative research: Issues in the development of meta-interpretation. International Journal of Social Research Methodology. 2008; 11(1): 13-28

44. Thomas J, Harden A. Method for the thematic synthesis of qualitative research in systematic reviews. BMC Medical Research Methodology. 2008; 8(45):1-10

45. Gilson L, Qualitative research synthesis for health policy analysis: what does it entail and what does it offer? Health Policy and Planning. 2014; 29 (suppl 3): iii1-iii5

46. Noblit GW, Hare RD. Meta-Ethnography: Synthesizing Qualitative Studies. London: Sage; 1988.

47. Barnet-Page E, Thomas J. Methods for the synthesis of qualitative research: a critical review. BMC Medical Research Methodology. 2009; 9 (59) 1-11

48. Elmore RE. Organizational models of programme implementation. Public Policy. 1978; 26: $185-228$.

49. WHO Quality of care: a process for making strategic choices in health systems. Geneva: World Health Organisation Press; 2006

50. Ministry of Health, Botswana Policy on HIV and AIDS, Revised Edition, National AIDS Coordinating Agency, 2012.

51. Mugwagwa J, Edwards D and de Haan S. Assessing the implementation and influence of policies that support research and innovation systems for health: the cases of Mozambique, Senegal, and Tanzania. Health Research Policy and Systems 2015; 13:21. DOI 10.1186/s12961-015-0010-2

52. Hyder AA, Alonge O, He S, Wadhwaniya S, Rahman F, Rahman A and Arifeen SEL. A Framework for Addressing Implementation Gap in Global Drowning Prevention Interventions: Experiences from Bangladesh. Journal of Health Population Nutrition 2014; 32(4):564-576 
53. De Savigny D and Taghreed Adam T (Eds). 2009. Systems thinking for health systems strengthening. Alliance for Health Policy and Systems Research, WHO, 2009.

54. Ntata PRT. (2007) Equity in access to ARV drugs in Malawi. SAHARA-J: Journal of Social Aspects of HIV/AIDS, 4:1, 564-574, DOI:10.1080/17290376.2007.9724818

55. Hunter DJ. Public health policy. Cambridge, Polity Press; 2003.

56. Aragon, A. O., \& Macedo, J. C. (2010). A 'systemic theories of change' approach for purposeful capacity development. IDS Bulletin, (41), 87-99.

57. Weed M. A potential method for the interpretive synthesis of qualitative research: Issues in the development of meta-interpretation. International Journal of Social Research Methodology. 2008; 11(1): 13-28. 